\title{
VIEWER SAMPLING AND QUALITY SIGNALING IN A TELEVISION MARKET
}

\section{Levent Çelik}
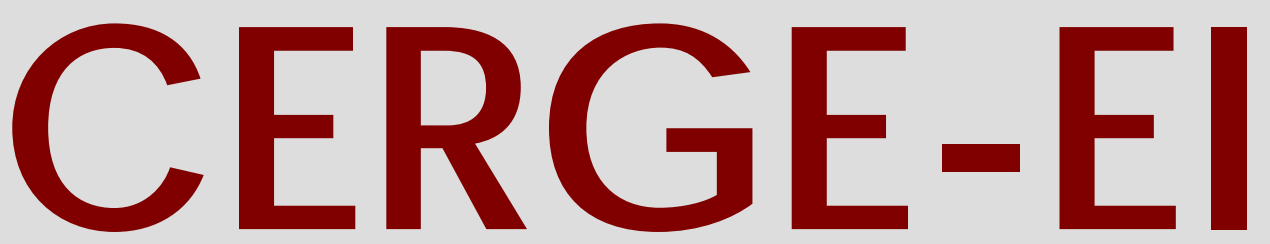

Charles University Centerfor Economic Research and Graduate Education Academy of Sciences of the Czech Republic Ec onomic s Institute 


\title{
Working Paper Series 363 (ISSN 1211-3298)
}

\section{Viewer Sampling and Quality Signaling in a Television Market}

\author{
Levent Çelik
}

CERGE-EI

Prague, September 2008 
ISBN 978-80-7343-163-1 (Univerzita Karlova. Centrum pro ekonomický výzkum a doktorské studium)

ISBN 978-80-7344-152-4 (Národohospodářský ústav AV ČR, v.v.i.) 


\title{
Viewer Sampling and Quality Signaling in a Television Market ${ }^{*}$
}

\author{
Levent Çelik ${ }^{\dagger}$
}

September, 2008

\begin{abstract}
This paper analyzes a single television station's choice of airing tune-ins (preview advertisements). I consider two consecutive programs located along a unit line. Potential viewers know the earlier program but are uncertain about the later one. They may learn it through a tune-in if they watch the earlier program and the television station chooses to air a tune-in, or by directly sampling it for a few minutes. If the sampling cost is sufficiently low, the unique perfect Bayesian equilibrium (PBE) exhibits no tune-ins. Otherwise, the unique PBE involves a tune-in unless the two programs are too dissimilar. When the programs are also quality-differentiated, the willingness to air a tune-in, and thus to disclose location information, may be sufficient to signal high quality without any dissipative advertising.
\end{abstract}

\begin{abstract}
Abstrakt
Tento článek analyzuje rozhodování jedné televizní stanice o vysílání upoutávek (tzv. “tune-ins”). Uvažuji dva po sobě následující pořady umístěné na jednotkové úsečce. Potencionální diváci znají předchozí program, ale nejsou si jistí o tom následujícím. Informace o následujícím pořadu mohou získat z upoutávek, které jsou umístěny v předchozím pořadu, pokud se je ovšem televizní stanice rozhodne vysílat, popř. Tyto informace mohou získat sledováním prvních několika minut. Pokud je cena za sledování prvních minut dostatečně nízká, jednoznačný perfektní Bayesovský rovnovážný bod (PBE) neobsahuje upoutávky. Jinak PBE zahrnuje upoutávky, pokud ovšem oba pořady nejsou př́liš rozdílné. Pořady se mohou lišit i v kvalitě, přičemž je-li mezi nimi kvalitativně velký rozdíl, ochota vysílat upoutávky, a tudíž odhalit polohu, může být dostatečná k naznačení vysoké kvality bez zbytečné propagace.
\end{abstract}

Keywords: Information Disclosure, Tune-ins, Uncertainty, Sampling, Signaling. JEL Classification: D83, L82, M37.

\footnotetext{
* I am grateful to Simon Anderson and Maxim Engers for their invaluable help during the progress of this paper. Thanks also go to Bilgehan Karabay, Krešimir Žigić and Robin-Eliece Mercury for helpful suggestions. I am responsible for all errors.

${ }^{\dagger}$ Address: CERGE-EI (a joint workplace of the Center for Economic Research and Graduate Education, Charles University, and the Economics Institute of the Academy of Sciences of the Czech Republic), P.O.Box 882, Politickych veznu 7, 111 21, Prague 1, Czech Republic. Email: celik@,cerge-ei.cz.
} 


\section{Introduction}

It is common in the literature on informative advertising to assume that consumers are initially unaware of market existence or that search costs are prohibitively high so that consumers never engage in searching. ${ }^{1}$ Thus, advertisements (henceforth, ads) inform them about product existence along with several other product characteristics. Since consumers are ex-ante unaware of the market structure, they do not make any inferences for the products about which they have not been informed through ads. In several consumer markets, however, market existence is common knowledge and/or consumers actively search for product information. The television (henceforth, TV) industry is a good example. Although many people may have limited or even no information about program attributes, the existence of TV programs is common knowledge to everyone. ${ }^{2}$

In Çelik (2008a), I take a look at the extent to which a single TV station is willing to air tune-ins when viewers cannot switch their TV off during a program once they start watching it. The model is developed in a simple Hotelling framework in which there is a continuum of potential viewers distinguished by their ideal programs. This is represented by assigning to each potential viewer a unique location along the unit line. As usual in Hotelling models, a viewer's net utility is lower the further away the actual program is from her ideal program. The TV station airs two consecutive programs. The location of the first program is assumed to be common knowledge. The location of the second program is ex-ante unknown to viewers. They have a prior belief for its location that is described by a quite general probability density function. They do, however, know that the TV station is privately informed about its location. Therefore, they rationally expect the TV station to share this information with the first-period audience if it is a profitable strategy to do so. The cost of airing a tune-in is the forgone revenue from a commercial ad during the first program.

I characterize in Çelik (2008a) the perfect Bayesian equilibria (PBE) for different values of the maximal utility a viewer can enjoy watching a program. If this value is not too high, then a PBE exists in which the TV station airs a tune-in whenever the two programs are similar

\footnotetext{
${ }^{1}$ For examples, see Grossman and Shapiro (1984) and Christou and Vettas (2008).

${ }^{2}$ The lack of information about program attributes may be due to the fact that the programs are newly introduced, or that the costs associated with gaining information are relatively high. Furthermore, individuals have limited memories.
} 
enough. There are some viewers who watch the first program just to observe the tune-in decision of the TV station. In the absence of a tune-in, no viewer within the first-period audience keeps watching TV. This PBE is unique if viewers' prior beliefs are not skewed to the right very much. I also find that there are no PBEs in which the TV station airs a tune-in for all program locations. I then analyze a social planner's problem who cares for viewer well-being as well. I find that the market performs sub-optimally in the sense that there always exists an equilibrium in which the social planner airs a tune-in for a wider range of programs.

Çelik (2008a) assumes that viewers watch a program until the end once they start watching it. This includes situations in which a program may turn out to be a bad match for a viewer. In this paper, I introduce program sampling whereby viewers can turn their TV off after a few minutes if they do not like the program. While this process fully reveals the true location of the program, it entails some cost, referred to as the "sampling cost". It is interpreted as the amount of the forgone utility that an individual would have enjoyed had she chosen not to watch TV.

I only focus on the equilibria of Çelik (2008a) that involves some viewers who watch the first program just to observe the tune-in decision of the TV station. For simplicity, I assume that viewers' prior beliefs are described by a uniform probability density function. I find that if the sampling cost is sufficiently low, the TV station does not air any tune-ins. Otherwise, there is a threshold program location up to which the TV station airs a tune-in.

The process of costly sampling plays a crucial role for two reasons. First, for an equilibrium that involves the use of tune-ins to exist, the sampling cost has to be positive. Had it been zero, viewers could costlessly learn a program's location and make their decisions without any uncertainty. Therefore, there would be no need for tune-ins. Second, a positive sampling cost may create an incentive for a station to choose not to air a tune-in. This is because the cost of sampling becomes sunk once a viewer chooses to engage in sampling. That is, when there is costly sampling, some individuals may end up watching a program that they would not choose to watch with complete information. By the same token, an individual's final decision may not be the one that maximizes her utility with complete information.

Certain programs are advertised several times during an ongoing program. This, however, is not completely due to high revenues that TV stations expect to generate from the advertised programs. Although about $80 \%$ of the network commercial time is sold in the up-front market 
during May for the upcoming season and the price paid by advertisers depends on the expected audience size, TV stations are bound to make up for the difference between the expected and the actual audience sizes should the former exceed the latter. Therefore, the TV stations' intention for airing several tune-ins for the same program may be to signal that program's high quality. I analyze this possibility as an extension of the main model with program sampling. To do this, I extend the model by allowing TV programs to be differentiated along two dimensions: one horizontal, one vertical. The vertical dimension is interpreted as the quality of a program which, I assume, is either high or low. If the upcoming program is one of low quality, the TV station may try to mislead viewers so as to attract more viewers. The resulting equilibrium depends on the location of the second program, and there are both separating and pooling PBEs. Most importantly, airing the quality-certainty optimal number of tune-ins - which is one - may be sufficient to signal high quality in a separating PBE. There are program locations for which only a TV station with a high-quality program can afford to air one tune-in, i.e., these programs do not generate enough of an audience to meet the cost of the tune-in when the upcoming program has a low quality since some viewers will switch off after realizing its actual quality.

The paper is organized as follows. The next section presents the benchmark model without program sampling. Section 3 extends the benchmark model by allowing viewers to turn off their TV after sampling a program. Section 4 discusses the implications of vertical differentitation. Finally, section 5 concludes.

\section{Benchmark Model}

There is a single TV station, which airs two consecutive programs $x_{1}$ and $x_{2}$, where $x_{t}$ represents the location of the program in period $t$ over the unit interval. The locations of both programs are known to the TV station. It is assumed that $x_{1}=0$, while $x_{2}$ can be located anywhere on the unit line. The programs are of the same length. The production costs are assumed to be sunk and the same for both programs, and are set to zero for simplicity. There is a discrete number, $A>1$, of time slots to be allocated to non-program content during each program, where $A$ is taken as exogenous. ${ }^{3}$ Thus, it may be considered as a sub-game of a larger

\footnotetext{
${ }^{3}$ While U.S. broadcasters are free to choose the amount of their non-program minutes, advertising ceilings are imposed on broadcasters in most European countries. Therefore, in most cases, especially in the prime-time, the
} 
game in which the choices of program locations and the amount of non-program minutes are already made.

There is a large number of advertisers, each willing to pay up to $\$ p$ per viewer reached for placing a commercial during a program. Each commercial is one time-slot long. Alternatively, the TV station may choose to air a tune-in (or tune-ins) during the first program for the purpose of promoting the next program. The production of a tune-in does not entail any costs. A tune-in has the same length as a commercial. The TV station splits the available $A$ ads during the first program between commercials and tune-ins (so, an ad may be in the form of a commercial or a tune-in). Hence, the TV station incurs an opportunity cost for placing tune-ins. The TV station cannot lie in a tune-in, i.e., the TV station is legally bound to advertise a preview of the actual program in the tune-in, and the tune-in is fully informative. Finally, the objective of the TV station is to maximize its total advertising revenue, which is generated by payments received from advertisers for placing commercials.

On the other side of the market, there is a continuum of $N$ potential viewers who are uniformly distributed along the unit interval with respect to their ideal programs. To each possible program location, there corresponds a viewer for whom that program is ideal. A viewer who is located at $\lambda$ obtains a net utility $u(\lambda, x)=v-|\lambda-x|$ from watching a program located at $x \cdot{ }^{4,5}$ Once a viewer chooses to watch a program, she is assumed to watch it until the end. Viewers' locations stay the same across the two periods. Not watching TV yields zero benefit. $^{6}$

In each period, viewers choose between watching or not watching TV. An individual's objective is to make the decision at each time that maximizes her total utility. Viewers are

amount of non-program minutes that maximizes a broadcaster's revenue falls below the imposed ceiling. There are also technical reasons for making this assumption. First, if TV stations were allowed to choose the amount of non-program minutes, then people would rationally form prior beliefs about it. Second, and most importantly, the amount of non-program minutes in the first period would possibly provide a signal for the location of the second program. Addressing these issues is beyond the scope of this paper, since the main focus is on the role of tune-ins. However, doing so would be an excellent area for future research.

${ }^{4}$ The gross utility $v$ can capture how interruptions during a program affect a viewer. Specifically, the effect of an increase (a decrease) in the nuisance cost of a commercial on a viewer's utility can be captured by lowering (raising) the gross utility. Note that, in this formulation, tune-ins also create a nuisance.

${ }^{5}$ Alternatively, $v$ can be interpreted as the quality of a program which enters into everyone's utility in the same way.

${ }^{6} \mathrm{~A}$ constant, $t$, can be put in front of $|\lambda-x|$ that measures the disutility associated with one unit of distance from the ideal program location. However, since the value of not watching TV is zero, utility can easily be expressed as $r-|\lambda-x|$, where $r=\frac{v}{t}$. 
assumed to be uncertain only about the location of the program in the second period, i.e., they know $x_{1}=0$ with certainty, while they hold prior beliefs for $x_{2} \cdot{ }^{7}$ They know that the TV station is privately informed about $x_{2}$. When making their viewing decisions in the first period, viewers consider not only their current utilities, but also the expected informational benefits they may obtain by seeing a tune-in for the second program. They have identical prior beliefs for the location of the second program, which are summarized by a uniform density function defined over $[0,1]$.

The timing of the game is as follows. First, viewers make their first-period decisions that maximize their expected two-period utilities. The first program starts, and during its progress, the TV station makes its tune-in decision. After the first program ends, if the TV station aired a tune-in, the first-period viewers learn the exact location of the second program. If the TV station did not air a tune-in, they update their beliefs accordingly. Finally, viewers make their second-period optimal decisions and payoffs are realized. As a tie-breaking rule, I assume that the TV station airs a tune-in whenever it is indifferent between airing and not airing one, and that people do watch TV whenever they are indifferent between watching and not watching. ${ }^{8}$

The equilibrium concept used is perfect Bayesian equilibrium (PBE). That is, the TV station makes an optimal tune-in decision taking into account the inferences viewers make in the absence of a tune-in, and in turn, viewers make optimal decisions (correctly) anticipating the TV station's strategy. In particular, viewers' inferences (or posterior beliefs) about the location of the second program following no tune-ins during the first program must be correct.

As a result of the tie-breaking rule, the TV station's optimal tune-in strategy is airing a tune-in with certainty if the resulting advertising revenue exceeds the revenue that it would earn without airing any tune-ins. Since a tune-in is assumed to be fully informative, and viewers watch a program until the end, the TV station airs only one tune-in. Viewers form beliefs about when the TV station would air a tune-in. These beliefs are described by a set of points $\Omega$ such that viewers ex-ante anticipate seeing a tune-in for the second program whenever $x_{2} \in \Omega$.

$\Omega$ is determined in equilibrium by viewers' anticipation for the TV station's tune-in strategy

\footnotetext{
${ }^{7}$ The fact that viewers know the location of the first program is without loss of generality since there are no tune-ins for it. It can practically be thought of as the evening news program, which everybody knows.

${ }^{8}$ Tie-breaking rules are imposed in order to rule out mixed strategy equilibria at the states of indifference. The specifics of the tie-breaking rule are without loss of generality since the distribution of program locations as well as of people's ideal programs are both continuous.
} 
corresponding to every possible program location. Let the binary variable $q \in\{0,1\}$ represent the TV station's tune-in decision, where $q=0$ when it does not air a tune-in and $q=1$ when it does. The marginal benefit of airing a tune-in is the marginal second-period advertising revenue as a result of a higher audience size. The only source of revenue for the TV station is the payments received from the advertisers. Thus, the marginal revenue due to a tune-in can be expressed as $A p N\left[s_{2}\left(x_{2} \mid q=1\right)-s_{2}\left(x_{2} \mid q=0\right)\right]$, where $s_{2}\left(x_{2} \mid q\right)$ is the fraction of viewers watching a program located at $x_{2}$ in the second period conditional on the realization of $q$. The cost is the forgone revenue that the TV station could have earned in the first period by selling the time used for the tune-in to an advertiser. So, it is given by $p N s_{1}$, where $s_{1}$ is the fraction of viewers watching the first program. Hence, from the viewers' point of view, the optimal tune-in strategy of the TV station as a function of $x_{2}$ is

$$
q\left(x_{2}\right)= \begin{cases}1, & s_{2}\left(x_{2} \mid q=1\right)-s_{2}\left(x_{2} \mid q=0\right) \geq \frac{s_{1}}{A} \\ 0, & \text { otherwise }\end{cases}
$$

In Çelik (2008a), I show that $\Omega$ is a closed interval or an empty set in every PBE. Let $\Omega=\left[x_{L}, x_{H}\right]$ with the understanding that $\Omega=\varnothing$ if $x_{L}=x_{H}$. Consider a viewer whose ideal program is $\lambda>v$. This viewer's optimal decision in the first period can be described as follows. If she watches the first program and sees a tune-in for the second program, she would watch the second program as well provided that its location is at most $v$ units apart from her ideal program. So, her ex-ante expected utility in this case is given by $\int_{\max \left\{x_{L}, \lambda-v\right\}}^{\min \left\{\lambda+v, x_{H}\right\}} u(\lambda, x) d x$. If she watches the first program and does not see a tune-in, she would keep watching TV provided that her updated expected utility is non-negative. So, her ex-ante expected utility in this case is $\max \left\{0, \int_{0}^{x_{L}} u(\lambda, x) d x+\int_{x_{H}}^{1} u(\lambda, x) d x\right\}$. Finally, in case she does not watch the first program, she would base her decision on her prior belief and will choose to watch the second program if $\int_{0}^{1} u(\lambda, x) d x \geq 0$. Hence, the benefit of watching the first program for this viewer, which I denote with $B(\lambda)$, can be expressed as

$$
\begin{aligned}
B(\lambda)= & \int_{\max \left\{x_{L}, \lambda-v\right\}}^{\min \left\{x_{H}, \lambda+v\right\}} u(\lambda, x) d x+\max \left\{0, \int_{0}^{x_{L}} u(\lambda, x) d x+\int_{x_{H}}^{1} u(\lambda, x) d x\right\} \\
& -\max \left\{0, \int_{0}^{1} u(\lambda, x) d x\right\} .
\end{aligned}
$$

Without any potential information gains, this viewer would not watch the first program since her direct utility from watching it, $(v-\lambda)$, is negative. However, $B(\lambda)$ may be positive. 
Thus, her optimal first-period decision is to watch TV when $B(\lambda) \geq \lambda-v$. The value of $\lambda$ for which $B(\lambda)=\lambda-v$ will be denoted by $\hat{\lambda}$.

Note that all of the three terms in $B(\lambda)$ are continuous functions of $\lambda$. Even though $B(\lambda)$ may display kinks, it does not have any discontinuities. Furthermore, since $\partial u(\lambda, x) / \partial \lambda$ is at most 1 , and $B(\lambda)$ is expressed in expectations, $\partial B(\lambda) / \partial \lambda<1$ for all values of $\lambda$. So, $B(\lambda)-$ $(\lambda-v)$ must be monotonically decreasing in $\lambda$. In other words, marginally changing a viewer's location in the first period may increase or decrease her informational benefits associated with watching the first program. However, relocation directly affects her first-period utility, too. The latter effect dominates the former one, and therefore, we have $\partial(B(\lambda)-(\lambda-v)) / \partial \lambda<0$.

Viewers with $\lambda>\hat{\lambda}$ for whom $\int_{0}^{1} u(\lambda, x) d x \geq 0$ only watch the second program. Thus, their decisions do not depend on the actual tune-in decision of the TV station. Similarly, when making its tune-in strategy, the TV station does not consider these viewers. Therefore, I will suppress these viewers for the remainder of the paper unless I state otherwise.

In Çelik (2008a), I characterize the PBE under a more general prior belief that includes the uniform probability density function as a special case. The following result is due to the first three propositions of Çelik (2008a). ${ }^{9}$

Proposition 1 Suppose that program sampling is sufficiently costly so that people stay tuned until a program ends if they chose to watch it.

(i) If $v \geq \frac{A}{2+A}$, the unique PBE is described by $\hat{\lambda}=v$ and $\Omega=\varnothing$.

(ii) If $\frac{A}{1+2 A} \leq v<\frac{A}{2+A}$, the unique PBE is described by $\hat{\lambda}=v$ and $\Omega=\left[0, x_{H}\right]$, where $x_{H}=1-\frac{2 v}{A}$. The first-period viewers with $\lambda \in\left[\frac{1+x_{H}}{2}-v, v\right]$ continue to watch $T V$ in the absence of a tune-in, while all others switch off.

(iii) If $v<\frac{A}{1+2 A}$, the unique PBE is described by $\hat{\lambda} \in\left(v, \frac{A}{1+2 A}\right)$ and $\Omega=\left[0, x_{H}\right], x_{H}>v$, where $\hat{\lambda}$ and $x_{H}$ are uniquely determined by the following two equations:

$$
\begin{gathered}
x_{H}=v+\left(1-\frac{1}{A}\right) \hat{\lambda} \\
\hat{\lambda}=v+\int_{\hat{\lambda}-v}^{x_{H}}(v-|\hat{\lambda}-x|) d x-\max \left\{0, \int_{0}^{1}(v-|\hat{\lambda}-x|) d x\right\} .
\end{gathered}
$$

In the absence of a tune-in, none of the first-period viewers watch the second program.

\footnotetext{
${ }^{9}$ Please refer to Çelik (2008a) for the details.
} 
When $v$ is not too large, there is a unique PBE described by a binary tune-in strategy (air a tune-in or not). The TV station airs a tune-in whenever the location of the second program exceeds a certain threshold. In other words, the TV station airs a tune-in unless the two programs are too dissimilar. Before deciding to watch TV in the first period, viewers consider both their first period utilities and the associated informational benefits. When $v<\frac{A}{1+2 A}$, some viewers watch the first program just to observe the tune-in decision of the TV station. In case there are no tune-ins, all first-period viewers switch their TV off. Knowing that viewers will correctly anticipate the resulting tune-in scheme, it never pays off for the TV station to deviate from this equilibrium decision rule.

\section{Program Sampling}

In this section, I introduce program sampling whereby people can sample the first few minutes of the second program, if they wish, before they make their final second-period decision. While this process fully reveals the true location of the program, it entails some cost, denoted by $c>0$ and referred to as the "sampling cost". This cost is incurred only if an individual opts out after sampling the program and thus enjoys the remaining part of the outside option. It should be interpreted as the amount of the forgone utility that an individual would have enjoyed had she chosen the outside option as the first thing, rather than sampling the program. Therefore, if an individual chooses to turn her TV off after sampling the second program, her net second-period benefit is $-c$.

Since program sampling acts as a substitute to seeing a tune-in, the TV station now has a lesser incentive for airing a tune-in. Therefore, in this section, I focus on the third case of Proposition 1, namely when $v<\frac{A}{1+2 A}$. It is clear that all equilibria will still have the form $\Omega=\left[0, x_{H}\right]$ or $\Omega=\varnothing$.

Assumption $1 v<\frac{A}{1+2 A}$.

The model is now slightly more complicated than the benchmark case because the viewers have more options. Given anticipations $\Omega$ for the optimal tune-in decision of the TV station, an individual with $\lambda>v$ makes a cost-benefit analysis to find her optimal first period decision. 
Take an individual whose ideal program location is between $v$ and $v+c .{ }^{10}$ If she watches the first program and sees a tune-in, she would watch the second program too provided that the advertised program is at most $v$ units apart from her location. If she watches the first program and does not see a tune-in, she would have to decide whether she should sample the second program or not. She would choose to sample if her posterior expected utility of doing so is non-negative. Given that she chose to sample it, she continues to watch it until the end unless the program location turns out to be more than $v+c$ units apart from her location. If she does not watch the first program, she would base her decision to sample the second program or not on her prior beliefs. She would choose to sample if the expected benefit of doing so exceeds its cost and would keep watching unless the program location is more than $v+c$ units apart from her location. So, the benefits of watching the first program for an individual with location $\lambda>v$ can be expressed as follows:

$$
\begin{aligned}
B(\lambda)= & \int_{\lambda-v}^{x_{H}} u(\lambda, x) d x+\max \left\{0, \int_{x_{H}}^{\lambda+v+c} u(\lambda, x) d x-(1-(\lambda+v+c)) c\right\} \\
& -\max \left\{0, \int_{0}^{\lambda+v+c} u(\lambda, x) d x-(1-(\lambda+v+c)) c\right\} .
\end{aligned}
$$

Each term in $B(\lambda)$ is analogous to the terms given in equation (2). The only difference is that we now have additional terms accounting for program sampling. For instance, if this viewer watches the first program and does not see a tune-in, she may choose to sample the second program. But the program may turn out to be more than $v+c$ units apart from her location, in which case she would simply turn off and incur the sampling cost. This is captured by the term $(1-(\lambda+v+c)) c$.

Lemma 1 Suppose for some $\lambda \geq v$

$$
\int_{x_{H}}^{\lambda+v+c} u(\lambda, x) d x-(1-(\lambda+v+c)) c>0 .
$$

Then, no viewer with an ideal program location $\lambda>v$ watches $T V$ in the first period, i.e., $\hat{\lambda}=v$.

\footnotetext{
${ }^{10}$ Note that when program sampling is possible, $v \leq \hat{\lambda}<v+c$.
} 
Lemma 1 says that if the sampling cost is sufficiently small (or $v$ is sufficiently large) such that a viewer located at $\lambda>v$ samples the second program even after watching the first one and seeing no tune-ins, then she would simply not watch the first program. This is exactly why I focus on lower values of $v$ as stated in Assumption 1. So, for sufficiently low values of the sampling cost, the absence of a tune-in no longer substitutes for program sampling for some viewers.

It is possible that no tune-ins prevail in equilibrium if the sampling cost is sufficiently low. As discussed earlier, if the beliefs are such that $\Omega$ is non-empty, then it must be true that $v \in \Omega$. This directly follows from the specification of the model; $x_{2}=v$ provides the TV station with the highest possible audience size. By Lemma 1, if some viewers with $\lambda>v$ watch the first program, then it must be true that

$$
\int_{x_{H}}^{\lambda+v+c} u(\lambda, x) d x-(1-(\lambda+v+c)) c<0 .
$$

If $\Omega=\varnothing$, then no viewer with $\lambda>v$ watch TV in the first period. Intuitively, this is because an equilibrium involving a tune-in for some program types must involve a tune-in for $x_{2}$, say for $x_{2}=v$, and if such an equilibrium existed, all of the first period audience would watch the second program when $x_{2}=v$.

To characterize the no tune-in equilibrium, suppose beliefs of people are given by $\Omega=$ $(0, v)$. The second-period decisions of the first-period audience conditional on $q=0$ are determined by the sign of

$$
\int_{v}^{\lambda+v+c}(v-(x-\lambda)) d x-(1-(\lambda+v+c)) c .
$$

Those for whom expression (7) is non-negative watch the second program. It is easy to show that this condition is satisfied when $\lambda+c \geq \sqrt{2(1-v) c}$. So, conditional on $q=0$, the total mass of viewers from the first-period audience who keep watching TV is given by $\max \{0, v+c-\sqrt{2(1-v) c}\}$.

If $s_{2}\left(x_{2} \mid q=1\right)-s_{2}\left(x_{2} \mid q=0\right)<\frac{s_{1}}{A}$ for all $x_{2} \in[0, v]$, there is no reason for people to believe that $\Omega$ is non-empty. This inequality is satisfied for all $x_{2} \in[0, v]$, when $c$ is such that $\sqrt{2(1-v) c}-c<\frac{v}{A}$. The left-hand side, $\sqrt{2(1-v) c}-c$, is increasing in $c$ for $c<\frac{1-v}{2}$. So, 
there is a cutoff value of $c$, denoted by $c_{1}$, such that, when $c<c_{1}$, the unique PBE is described by $q=0$ for all $x_{2} \in[0,1]$, and $\Omega=\varnothing$. Intuitively, when the sampling cost is sufficiently low, the TV station has no incentive to advertise its program since everyone will find it out anyhow.

Now suppose that $c \geq c_{1}$. Since $\sqrt{2(1-v) c}-c \geq \frac{v}{A}$ for all values of $c$ up to $\frac{1-v}{2}, \Omega=\varnothing$ cannot be supported as a PBE anymore. Viewers expect to see a tune-in for all programs up to a threshold location $x_{H}>v$. Formally, watching the first program is more costly than just sampling the second program for viewers with $\lambda<v$ when

$$
\int_{x_{H}}^{\lambda+v+c}(v-(x-\lambda)) d x-(1-(\lambda+v+c)) c \geq 0 .
$$

Suppose this expression is satisfied for some $\lambda<v$ and denote the cutoff viewer by $\tilde{\lambda}$. Then $\hat{\lambda}=v$ by Lemma 1 , and the TV station airs a tune-in for all $x_{2}$ that satisfies $\left(v-\left(x_{2}-\right.\right.$ $v))-(v-\tilde{\lambda}) \geq \frac{v}{A}$. Thus, $x_{H}=\tilde{\lambda}+\left(1-\frac{1}{A}\right) v$. Plugging this back into expression (8), one must impose the condition that $\tilde{\lambda} \leq v$. So, the unique PBE is given by $\Omega=\left[0, x_{H}\right]$, and $\hat{\lambda}=v$ when $c_{1} \leq c<c_{2}$, where $c_{2}$ is given by ${ }^{11}$

$$
c_{2}=1-2 v-\sqrt{(1-2 v)^{2}-\left(\frac{v}{A}\right)^{2}} .
$$

In this $\mathrm{PBE}$, no one with $\lambda>v$ watches the first program. However, some viewers, those with $\lambda \geq 1-\frac{\left(c+\frac{v}{A}\right)^{2}}{2 c}-\left(1-\frac{1}{A}\right) v$ to be more specific, choose to sample the second program in the absence of a tune-in. When $c \geq c_{2}$, on the other hand, the cost of sampling the second program conditional on not watching the first program exceeds the cost of watching the first program. So, we get a PBE similar to the one described in Proposition 1 (iii). Indeed, if the value of the sampling cost is sufficiently large, then we get exactly the same PBE as in Proposition 1 (iii). This happens when the equilibrium value of $\hat{\lambda}$ in Proposition 2 (iii) below is equal to the equilibrium value of $\hat{\lambda}$ in Proposition 1 (iii).

All of the discussion above is summarized in the following proposition. ${ }^{12}$

Proposition 2 Suppose that sampling a program is possible, but has a cost of $c>0$ if an individual does not continue watching.

\footnotetext{
${ }^{11} c_{2}$ can be found by locating the marginal first-period viewer who keeps watching TV in the absence of a tune-in given that $\Omega=\left[0, \lambda+\left(1-\frac{1}{A}\right) v\right]$ and then imposing the condition that this value cannot be greater than $v$.

${ }^{12}$ The proof is omitted since it is clear from the preceding discussion and from Proposition 1.
} 
(i) If $c<c_{1}$, the unique PBE is described by $\hat{\lambda}=v$, and $\Omega=\varnothing$. All first-period viewers sample the second program.

(ii) If $c_{1} \leq c<c_{2}$, the unique PBE is described by $\hat{\lambda}=v$, and $\Omega=\left[0, x_{H}\right]$, where $x_{H}=$ $1-\frac{\left(c+\frac{v}{A}\right)^{2}}{2 c}$. Some, but not all, of the first-period viewers continue to watch the second program in the absence of a tune-in.

(iii) If $c_{2} \leq c<c_{3}$, the unique PBE is described by $\hat{\lambda}>v$, and $\Omega=\left[0, x_{H}\right], x_{H}>v$, where $\hat{\lambda}$ and $x_{H}$ are uniquely determined by the following two equations:

$$
\begin{gathered}
x_{H}=v+\left(1-\frac{1}{A}\right) \hat{\lambda} \\
\hat{\lambda}=v+\int_{\hat{\lambda}-v}^{x_{H}} u(\lambda, x) d x-\max \left\{0, \int_{0}^{\lambda+v+c} u(\lambda, x) d x-(1-(\lambda+v+c)) c\right\} .
\end{gathered}
$$

In the absence of a tune-in, none of the first-period viewers watch the second program.

(iv) When $c \geq c_{3}$, the PBE described in Proposition 1 (iii) prevails.

Figure 1 (see page 21) shows how the location of the marginal viewer in the first period and the equilibrium value of $x_{H}$ evolve as a function of the sampling cost.

To summarize, in this extended model, two different equilibria may arise depending on the value of the sampling cost. If the sampling cost is sufficiently low, then the unique PBE exhibits no tune-ins. If it is sufficiently high, then the unique PBE involves a tune-in for the upcoming program unless the two programs are too dissimilar. An important implication in this case is that viewers rationally anticipate the range of programs for which the TV station would air a tune-in. Therefore, no one from the first period audience keeps watching TV unless there was a tune-in for the second program.

Comparing the results with the benchmark model, we see that the fear that an individual may end up watching a bad program until the end leads some viewers to gather early information by watching the first program. However, this is not necessarily good news for the TV station. Unless these viewers receive a tune-in, they will not keep watching TV. When it is possible to sample a program for a while, however, viewers are not as constrained because they do not have to watch a bad program until the end. Therefore, not as many viewers watch the first program just to alleviate their informational constraints. 


\section{Vertical Differentiation}

The model with program sampling can be extended to include a second dimension of differentiation. Below, I sketch the main implications of adding a quality dimension about which viewers are uncertain beforehand. I assume that any direct information the TV station may provide about quality in a tune-in is not reliable. This is a common assumption in the literature. For simplicity, suppose that there are only two quality levels, high or low, and that viewers' utility function is given by $u(\lambda, x)=v_{j}-|\lambda-x|, j=H, L$, where $v_{H}>v_{L}$. Also suppose that the first program is of low quality. For ease of exposition, the TV station is referred to as the "high-quality station" when its second program is of high quality, and as the "low-quality station" when it is of low quality.

The main findings of the previous section extend to this case, too. Namely, for values of $c$ that are not very small - an assumption I maintain in this section - there is a unique viewer for whom watching and not watching the first program yields the same expected utility. Let this viewer's location be denoted, as before, by $\hat{\lambda}$. Since the first program is assumed to be of low quality, the first-period audience comprises viewers with locations $\lambda<\hat{\lambda}$. Note that it is still true that $\hat{\lambda}-v_{L}<c$.

As before, it is optimal for the TV station to air a tune-in for the second program as long as it is similar enough with the first one. This only requires that the sampling cost is not too low. In the absence of a tune-in, no one from the first-period audience watches the second program regardless of its quality. Therefore, there is a unique program location $x_{H}^{L}$ such that the low-quality station advertises its upcoming program when $x_{2} \in\left[0, x_{H}^{L}\right]$. Similarly, there is a unique program location $x_{H}^{H}>x_{H}^{L}$ such that the high-quality station advertises its upcoming program when $x_{2} \in\left[0, x_{H}^{H}\right]$.

In a separating PBE, we need the low-quality station to behave in the same way as it would behave if viewers knew with certainty that the second program had a low quality. Therefore, it must be true that $x_{H}^{L}=v_{L}+\left(1-\frac{1}{A}\right) \hat{\lambda}$.

The incentive for the low-quality station to act as if its upcoming program has a high quality comes from the fact that program sampling is costly. Suppose the low-quality station claims in its tune-in that the upcoming program has a high quality, and that the viewers believe this statement. Those for whom watching a high-quality program yields a non-negative utility start 
to watch the second program. After a few minutes, they realize that the TV station actually lied in the tune-in; the program was one of low quality. While some of these viewers switch off at this point, not all do. Viewers whose ex-post utilities are at least as high as $-c$ would keep watching since the cost of sampling has already been sunk. So, when the low-quality station lies in a separating PBE, the increase in its second-period audience size is at most $c$.

An important result follows from the discussion above; in a separating PBE, only one tunein for a program located at $x_{2} \in\left(x_{H}^{L}+c, x_{H}^{H}\right]$ suffices to signal high quality. Given that the low-quality station does not air any tune-ins for $x_{2}>x_{H}^{L}$ in a separating PBE, it must not have any incentive to falsify viewers by airing a tune-in for $x_{2}>x_{H}^{L}+c$. Therefore, separation occurs with no distortion in the tune-in strategy. This result is in contrast with the existing literature on quality signaling. A high-quality firm is generally required to engage in dissipative advertising - also referred to as "money burning" - in order to correctly signal its quality. In the current setup, however, it is possible to signal high quality with no distortion in the advertising strategy by simply providing the location of the product. When this information deters a sufficient number of viewers from continuing to watch, it is correctly understood that the program must have a high quality.

For $x_{2} \leq x_{H}^{L}+c$, we must have a separating PBE in which the high-quality station airs more than one tune-in, and that it is not optimal for the low-quality station to mimic this strategy. The high-quality station would be willing to separate itself as long as the cost of airing the extra tune-in(s) does not exceed the extra revenue it would enjoy by separation. Hence, the high-quality station would do so if the extra audience size generated by separation is at least as high as $k \frac{\hat{\lambda}}{A}$, where $k$ is the number of extra tune-ins required for separation. If $c<\frac{\hat{\lambda}}{A}$, one extra tune-in would be sufficient for separation. If $\frac{\hat{\lambda}}{A}<c<\frac{2 \hat{\lambda}}{A}$, then two more tune-ins are required for separation. I will make the following assumption for the rest of the analysis.

Assumption $2 v_{H}-v_{L}>\frac{\hat{\lambda}}{A}>c$.

Separation is not possible when the location of the second program is close to 0 , i.e., when the two programs are more similar. This is because such a program would appeal to all of the first-period viewers regardless of its quality. Suppose the second program is also located at 0 . In a separating PBE, no viewer with $v_{L}<\lambda \leq \hat{\lambda}$ would sample the second program if they inferred that it has a low quality. If, on the other hand, they inferred that the second program 
has a high quality, then all of them would continue to watch. However, the high-quality station has to be willing to air an additional tune-in in the first period to separate itself. By separation, it gains an extra audience size of at most $\hat{\lambda}-v_{L}$. Since $\hat{\lambda}-v_{L}<c$, the gain by separation falls short of its cost, and therefore, the high-quality station would choose to pool. This argument is valid for all $x_{2}<v_{L}+\frac{\hat{\lambda}}{A}$.

To summarize, when the first program has a low quality, we have the following results. ${ }^{13}$

\section{Proposition 3 The following constitutes a PBE:}

(i) When $x_{2} \leq v_{L}+\frac{\hat{\lambda}}{A}$, there is no separating PBE in quality. Each type airs 'one' tune-in.

(ii) When $v_{L}+\frac{\hat{\lambda}}{A}<x_{2} \leq\left(1-\frac{1}{A}\right) \hat{\lambda}+\left(v_{L}+c\right)$, the high-quality station airs two tune-ins to signal high quality. The low-quality station airs one tune-in for $v_{L}+\frac{\hat{\lambda}}{A}<x_{2} \leq\left(1-\frac{1}{A}\right) \hat{\lambda}+v_{L}$ and airs none for $x_{2}>\left(1-\frac{1}{A}\right) \hat{\lambda}+v_{L}$.

(iii) When $\left(1-\frac{1}{A}\right) \hat{\lambda}+\left(v_{L}+c\right)<x_{2} \leq\left(1-\frac{1}{A}\right) \hat{\lambda}+v_{H}$, only the high-quality station airs one tune-in, and this is sufficient to signal high quality.

(iv) When $x_{2}>\left(1-\frac{1}{A}\right) \hat{\lambda}+v_{H}$, the TV station does not air any tune-ins regardless of its type. (so, there is no separation).

The strategies described in Proposition 3 satisfy individual rationality and incentive compatibility constraints for both station types. As mentioned before, the reason for why the highquality station airs 'two' tune-ins for separation comes from the specification that there is an integer number of tune-ins, and the assumption that $\frac{\hat{\lambda}}{A}>c$. More generally, letting $c=\frac{k \hat{\lambda}}{A}-\varepsilon$, we would need $k$ additional tune-ins by the high-quality station to signal quality. Figure 2 (see page 22) displays the posssible equilibria when the first program has a low quality.

Similar results are obtained when the first program has a high quality. The only difference is that separation by airing more tune-ins is now also possible for program locations that are sufficiently close to 0 . The reason is that there is now a higher number of viewers watching the first program, and therefore the high-quality station can gain enough by separation when $x_{2}<$ $\hat{\lambda}-\left(v_{L}+\frac{\hat{\lambda}}{A}\right)$. The possible equilibria in this case are depicted in Figure 3 (see page 23).

\footnotetext{
${ }^{13}$ The proof is omitted since the proposition is clear from the discussion that precedes it.
} 


\section{Conclusion}

In this paper, I have extended Çelik (2008a) to include program sampling. The main findings can be summarized as follows. When there is a single TV station offering two consecutive programs that are horizontally differentiated, two equilibria may arise depending on the value of the sampling cost viewers incur. If it is sufficiently low, the unique PBE exhibits no tune-ins. For higher values of the sampling cost, the unique PBE involves the TV station airing a tune-in for its upcoming program as long as it is similar enough with the first program.

I also analyze the role of tune-ins when the quality of the upcoming program is also unknown to viewers beforehand. In this scenerio, tune-ins do not only carry hard information, but also might signal the quality of the upcoming program. A high-quality monopolist may choose to air more than one tune-in for the same program to signal its quality even though the tune-in is fully informative. It may also be the case that for certain program locations, there is no need for dissipative advertising to signal quality. So, money burning is not always necessary for a TV station to signal high quality. This is because there are programs that only a TV station with a high-quality program can afford to advertise.

Analyzing the role of tune-ins in an oligolopolistic TV market requires modeling of people's switching behavior during a program. It is common to assume that people do not engage in multihoming, i.e., they consume only one product in every period. Furthermore, empirical data and research support the 'lead-in' effect as significant and is more than $60 \%$. Therefore, under the assumption that people cannot watch more than one program in a given period, each TV station actually acts like a monopolist to its current viewers. The only difference is there will be viewers who switch from one station to another. If the TV stations do not know each others' program locations when making their tune-in decisions, then their equilibrium tune-in strategies will be similar to the findings in this paper. If they do, on the other hand, the analysis gets complicated. Each station's tune-in decision may now indirectly disclose information about other stations' programs. This is what I study in Çelik (2008b) for a duopoly market. 


\section{Appendix}

Proof of Lemma 1 First observe that

$$
\frac{\partial\left[\int_{x_{H}}^{\lambda+v+c}(v-|\lambda-x|) d x+(1-(\lambda+v+c))(-c)\right]}{\partial \lambda}>0 \text { for } v<\lambda \leq v+c .
$$

Suppose $c$ is small enough as stated in the lemma. Then, the last term in $B(\lambda)$ must be positive for all $v<\lambda \leq v+c$. So, $B(\lambda) \geq(\lambda-v)$ when

$$
-\int_{0}^{\lambda-v} u(\lambda, x) d x \geq \lambda-v
$$

This inequality is can be satisfied with equality only when $\lambda=v$. So there is no $v<\lambda \leq$ $v+c$ such that $B(\lambda)=(\lambda-v)$. People with $\lambda>v+c$ never watch the first program since their first-period disutility exceeds the sampling cost. 


\section{References}

Anand, Bharat N. and Ron Shachar (1998), "The Effectiveness and Targeting of Television Advertising," Journal of Economics and Management Strategy, 7, 363-396.

Anand, Bharat N. and Ron Shachar (2005), "Advertising the Matchmaker," mimeo, Harvard Business School and Tel Aviv University.Anderson, Simon P., André de Palma and Jacques-F. Thisse (1992), Discrete Choice Theory of Product Differentiation, MIT Press, Cambridge.

Anderson, Simon P. and Jean J. Gabszewicz (2005), "The Media and Advertising: A Tale of Two-Sided Markets," working paper, University of Virginia and CORE, forthcoming in Handbook of Cultural Economics, eds. Victor Ginsburgh and David Throsby, Elsevier Science.

Anderson, Simon P. and Régis Renault (1999), "Pricing, Product Diversity, and Search Costs: A Bertrand-Chamberlin-Diamond Model," Rand Journal of Economics, 30:4, 719-735.

Anderson, Simon P. and Régis Renault (2006), “Advertising Content,” American Economic Review, 96:1, 93-113.

Bagwell, K. (2007), “The Economic Analysis of Advertising,” M. Armstrong and R. Porter, eds. Handbook of Industrial Organization Vol. 3, Amsterdam: North-Holland, 1701-1844.

Butters, Gerard R. (1977), "Equilibrium Distributions of Sales and Advertising Prices," Review of Economic Studies, 44:3, 465-491.

Christou, Charalambos and Nikolaos Vettas (2008), "On Informative Advertising and Product Differentiation,” International Journal of Industrial Organization, 26, 92-112.

Çelik, Levent (2008a), “Monopoly Provision of Tune-ins,” mimeo, CERGE-EI.

Çelik, Levent (2008b), "Strategic Informative Advertising in a Horizontally Differentiated Duopoly," mimeo, CERGE-EI.

Diamond, Peter A. (1971), “A Model of Price Adjustment,” Journal of Economic Theory, 3, 156-168.

Emerson, John W. and Ron Shachar (2000), “Cast Demographics, Unobserved Segments, and Heterogeneous Switching Costs in a Television Viewing Choice Model," Journal of Marketing Research, 37, 173-186.

Grossman, Gene and Carl Shapiro (1984), "Informative Advertising with Differentiated Products," Review of Economic Studies, 51, 63-81.

Hotelling, Harold (1929), “Stability in Competition,” Economic Journal, 39, 41-57. 
Kihlstrom, Richard E. and Michael H. Riordan (1984), “Advertising as a Signal,” Journal of Political Economy, 92, 427-450.

Meurer, Michael and Dale O. Stahl, II (1994), "Informative Advertising and Product Match," International Journal of Industrial Organization, 12, 1-19.

Milgrom, Paul R. and John M. Roberts (1986a), "Prices and Advertising as Signals of Product Quality," Journal of Political Economy, 94, 796-821.

Moraga-González, José Luis (2000), "Quality Uncertainty and Informative Advertising," International Journal of Industrial Organization, 18, 615-640.

Nelson, Phillip J. (1974), “Advertising as Information,” Journal of Political Economy, 82, $729-754$.

Roberts, Jacques and Dale O. Stahl, II (1993), "Informative Price Advertising in a Sequential Search Model," Econometrica, 61:3, 657-686.

Tirole, Jean (1988), The Theory of Industrial Organization, MIT Press, Cambridge. 


\section{FIGURE 1}

Evolution of $\hat{\lambda}$ and $x_{H}$ as a function of $c$

Figure 1.1 Location of the marginal viewer $(\hat{\lambda})$ in the first period

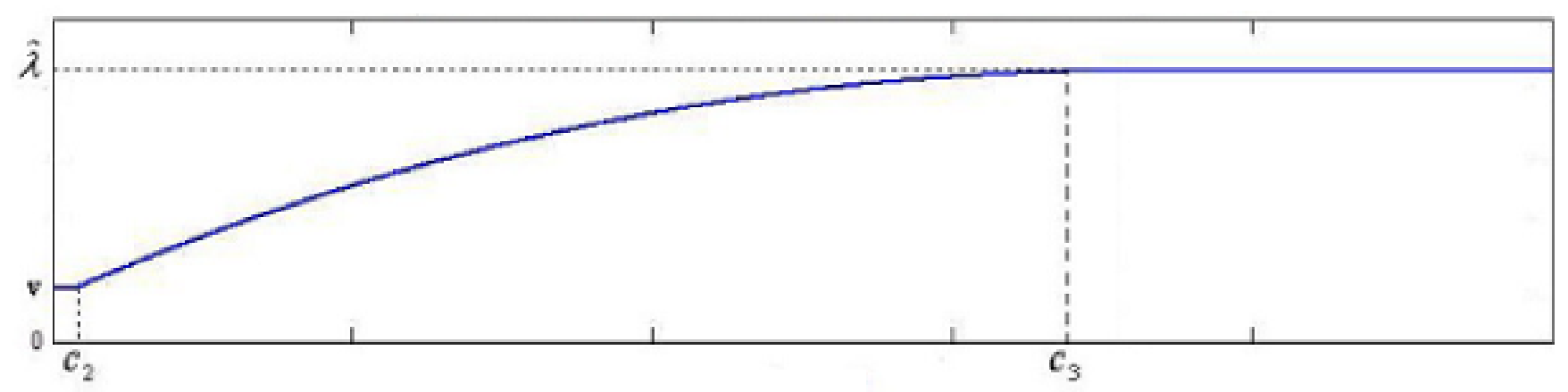

Figure 1.2 The threshold program location $\left(x_{H}\right)$

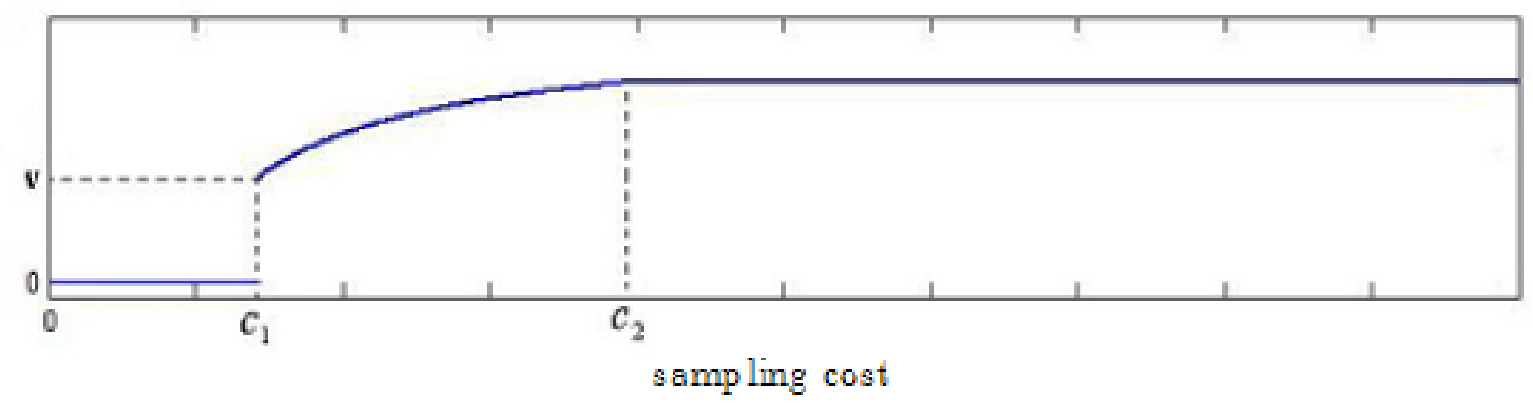




\section{FIGURE 2}

Quality signaling when the $1^{\text {st }}$ program has low quality

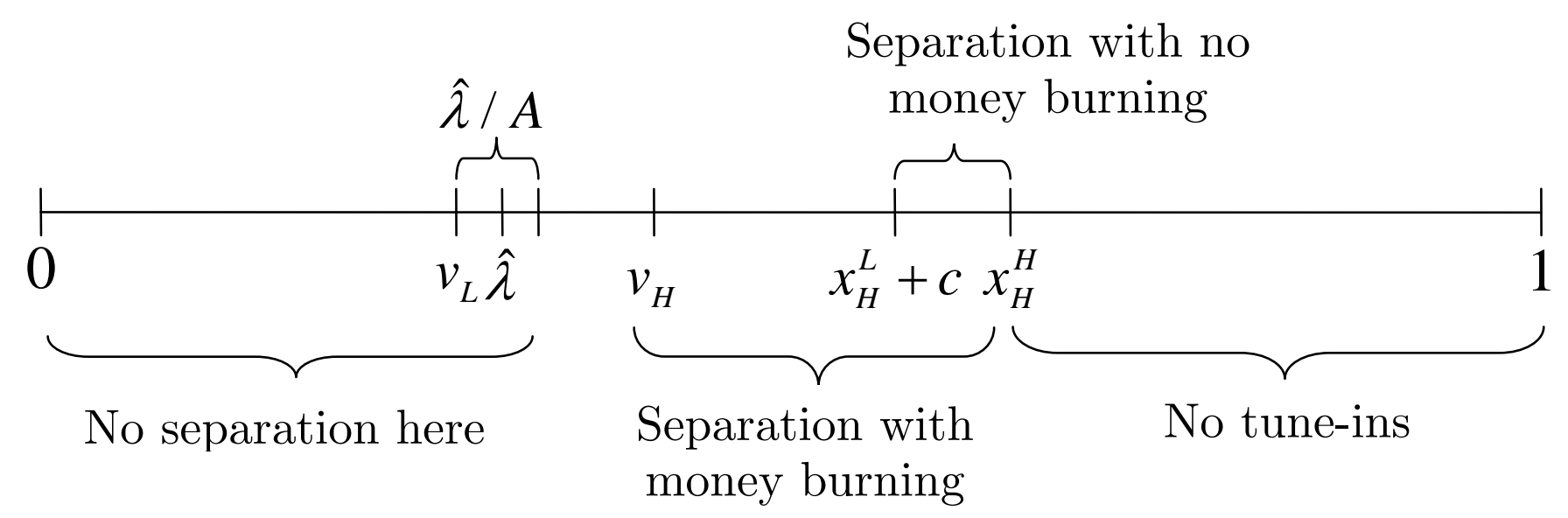




\section{FIGURE 3}

Quality signaling when the $1^{\text {st }}$ program has high quality

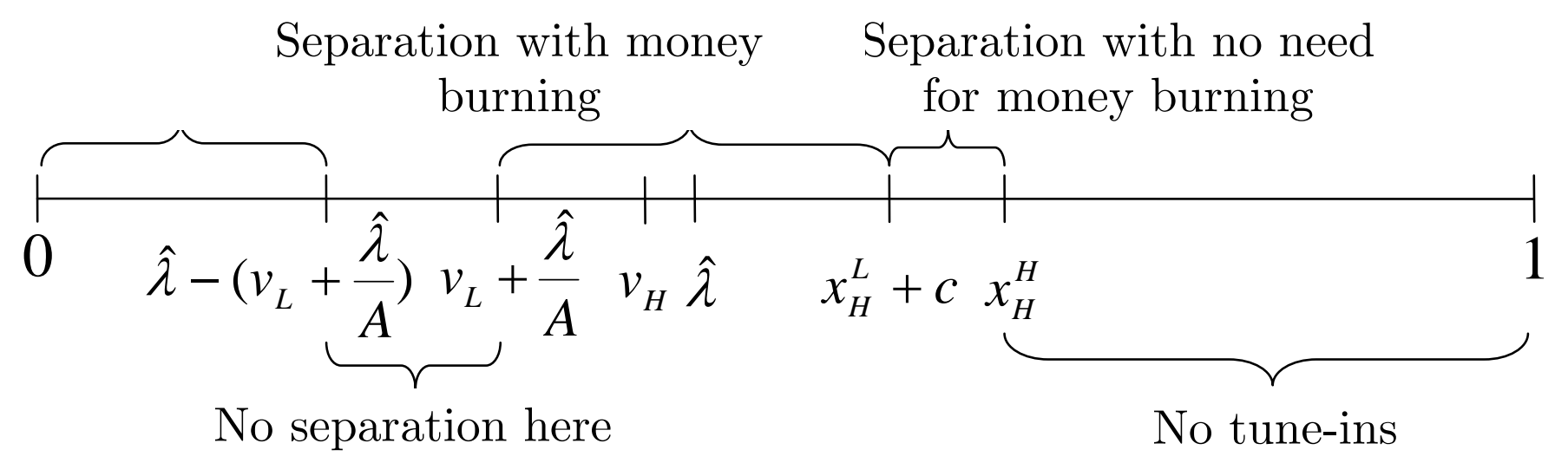


Individual researchers, as well as the on-line and printed versions of the CERGE-EI Working Papers (including their dissemination) were supported from the following institutional grants:

- Economic Aspects of EU and EMU Entry [Ekonomické aspekty vstupu do Evropské unie a Evropské měnové unie], No. AVOZ70850503, (2005-2010);

- Economic Impact of European Integration on the Czech Republic [Ekonomické dopady evropské integrace na ČR], No. MSM0021620846, (2005-2011);

Specific research support and/or other grants the researchers/publications benefited from are acknowledged at the beginning of the Paper.

(c) Levent Çelik, 2008.

All rights reserved. No part of this publication may be reproduced, stored in a retrieval system or transmitted in any form or by any means, electronic, mechanical or photocopying, recording, or otherwise without the prior permission of the publisher.

Published by

Charles University in Prague, Center for Economic Research and Graduate Education (CERGE) and

Economics Institute ASCR, v. v. i. (EI)

CERGE-El, Politických vězňŭ 7, 11121 Prague 1, tel.: +420 224005 153, Czech Republic.

Printed by CERGE-EI, Prague

Subscription: CERGE-EI homepage: http://www.cerge-ei.cz

Editors: Directors of CERGE and EI

Managing editors: Deputy Directors for Research of CERGE and EI

ISSN 1211-3298

ISBN 978-80-7343-163-1 (Univerzita Karlova. Centrum pro ekonomický výzkum

a doktorské studium)

ISBN 978-80-7344-152-4 (Národohospodářský ústav AV ČR, v. v. i.) 
CERGE-EI

P.O.BOX 882

Politických vězňů 7

11121 Praha 1

Czech Republic http://www.cerge-ei.cz 